\title{
Experimental Research on Microhardness and Wear Resistance of MB8 Magnesium Alloy Treated by Ultrasonic Impact
}

\author{
Yu Yingxia ${ }^{1}, \quad$ He Bolin $^{2}, \quad$ Lv Zongmin ${ }^{1}, \quad$ Lei Siyong $^{2}, \quad$ Xia Songsong $^{1}$ \\ ${ }^{1}$ East China Jiaotong University, Nanchang 330013, China; ${ }^{2}$ Key Laboratory for Conveyance and Equipment, Ministry of Education, \\ Nanchang 330013, China
}

\begin{abstract}
The surface of MB8 wrought magnesium alloy was treated by HJ-III type ultrasonic impact treating (UIT) machine. The microstructures of the treated surface were analyzed by an optical microscope, and the grain refining mechanism of UIT was investigated by High Resolution Transmission Electron Microscopy (HRTEM). The wear resistance of MB8 wrought magnesium alloy was experimentally researched both with the treated and untreated specimens. The effect of UIT process on the microstructure and microhardness were also investigated using scanning electron microscope (SEM) and microhardness tester. The results indicate that the grains on the top surfaces of MB8 are highly refined. The severe plastic deformation is formed by UIT, and the thickness of the plastic deformation layer is approximately $180 \mu \mathrm{m}$. The microhardness and wear resistance of the treated surface layer of MB8 can be enhanced significantly compared to that of the untreated specimens. The longer the UIT time, the greater of the microhardness and wear resistance the treated surface layer of MB8 will be. When the impact current is $1.2 \mathrm{~A}$ and impact time is 6 min, the microhardness and wear resistance of the treated sample is about $102.8 \%$ and $51.83 \%$ higher than that of the untreated specimen, respectively.
\end{abstract}

Key words: ultrasonic impact treating; MB8 wrought magnesium alloy; microstructure; hardness; wear resistance

In recent years, many components in the fields of automotive and aerospace are needed to reduce weight. Since weight reduction can get economical benefits in terms of energy consumption. Magnesium alloy is one of the lightest structure materials. Owing to the low density and high strength-to-weight ratio, magnesium alloys attract much attention of different industries ${ }^{[1,2]}$. Structural parts of the engine, power transmission and car body might be made of magnesium alloys in the future ${ }^{[3,4]}$. Despite these good properties, magnesium alloys still have some shortcomings, such as poor wear and corrosion resistance, which restrict their application in automotive, locomotive vehicles, aerospace, and so on ${ }^{[5-7]}$. Various approaches have been used to enhance the wear resistance of magnesium alloys, for example laser surface modification ${ }^{[8]}$, reinforcement of the metal matrix with ceramic particles and fibers ${ }^{[3,5]}$, ion implantation and physical vapor deposition (PVD) ${ }^{[9,10]}$.

Ultrasonic impact treatment (UIT) is a possible way to effectively improve the wear resistance, corrosion resistance and fatigue properties of metals and their alloys ${ }^{[11,12]}$. Compared to traditional surface cold working, UIT is claimed to be more efficient involving a complex effect of strain hardening and grain refinement to increase the strength and hardness of the metal surface and also a negative residual stress distribution in the metal surface. Although the UIT method has been developed for actual application, there are few researches about the effect of UIT on microhardness and wear resistance of the metals and their alloys especially for MB8 magnesium alloy. MB8 is one of the widely used wrought magnesium alloy and it possesses a good

Received date: July 15, 2016

Foundation item: National Natural Science Foundation of China (51265013); Natural Science Foundation of Jiangxi Province (20151BAB206007)

Corresponding author: He Bolin, Ph. D., Professor, School of Mechanical \& Electrical Engineering, East China Jiaotong University, Nanchang 330013, P. R. China, Tel: 0086-791-87046116, E-mail: hebolin@163.com

Copyright (C) 2017, Northwest Institute for Nonferrous Metal Research. Published by Elsevier BV. All rights reserved. 
combination of mechanical and physical properties. However, high friction and poor wear resistance are critical issues seriously restricting its practical application. In most cases, material failures occur on the surface due to wear, corrosion and fatigue. These failures are very sensitive to the microstructure and properties of the material surface ${ }^{[13,14]}$. Hence, optimization of the surface condition of the materials can be an effective approach to improve their properties and service life. In the present paper, the experimental work was designed to study the effect of ultrasonic impact treatment on the wear resistance and microhardness of MB8 wrought magnesium alloy and the wear mechanism was also discussed.

\section{Experiment}

The material studied was a Mg-Mn-Ce alloy (MB8 wrought magnesium alloy). The chemical composition and mechanical properties of the MB8 are shown in Table 1 and Table 2.

The impact treatment tests were carried out with HJ-III type ultrasonic impact machine. The ultrasonic generator can generate oscillation signal of about $18 \sim 27 \mathrm{kHz}$ that is converted to P-wave mechanical vibration energy through a transducer. The frequency and line speed of the vibration are $20 \mathrm{kHz}$ and $2 \sim 3 \mathrm{~m} / \mathrm{s}$, respectively. The acceleration is equivalent to 30,000 times gravity acceleration. Single-punch diameter is generally 8 $\mathrm{mm}$, and multi-punch's punch ranged side by side with a diameter of $2.5 \sim 3.5 \mathrm{~mm}$. The UIT equipment comprises a handheld tool and an electronic control box containing the ultrasonic generator. The tool is easy to operate and provides a good work environment with negligible noise and vibration. The UIT tool and pins are $3 \mathrm{~mm}$ in diameter.

In this research, the impact current was 1.2 ampere, and the impact time was 2, 4, and $6 \mathrm{~min}$. The treated and untreated
MB8 specimens are shown in Fig.1. The plate shape is a rectangle with size $100 \mathrm{~mm} \times 30 \mathrm{~mm} \times 8 \mathrm{~mm}$.

Surface microstructure of MB8 after UIT was determined by an optical microscope (OM, Zeiss Germany). A JEM-2100 High Resolution Transmission Electron Micros- cope (HRTEM) (JEOL, Japan) was used to investigate the micro-plastic deformation and grain refining mechanism of treated surface layer of MB8 alloy. Effect of ultrasonic impact treatment on the grain refining of the MB8 wrought alloy was discussed. The Vickers hardness of the specimens was tested using XHV-1000Z type hardness tester (CANY, China), with the loading and the loading time of $5 \mathrm{~N}$ and $10 \mathrm{~s}$ respectively. The worn surface analysis was carried out by an SJM-6360LA scanning electron microscope (JEOL, Japan).

The wear tests were investigated by a wear test machine of M-2000 model (Hebeixuangong, China) under the condition of room temperature and $40 \%$ relative humidity. The external load was $300 \mathrm{~N}$. The rotating speed of the down wear specimen was $200 \mathrm{r} / \mathrm{min}$.

\section{Results and Discussion}

\subsection{Microstructure and hardness}

After impact treating on the surface of MB8 Mg alloy, the treated surface microstructure is refined obviously, as shown in Fig.2. After UIT, severe plastic deformation is produced in the surface of MB8 alloy, and the maximum depth of the plastic deformation layer is about $260 \mu \mathrm{m}$, as shown in Fig. $2 \mathrm{~d}$. From Fig. 3 it can be seen that fine grains in the surface layer are obtained, and the grain size is less than $200 \mathrm{~nm}$. Meanwhile, high-density dislocation tangle (arrow tip A) is formed and the grain is highly refined. The severe plastic deformation on the surface of MB8 $\mathrm{Mg}$ alloy is obtained

Table 1 Chemical composition of $\mathrm{MB8}(\mathrm{wt} \%)$

\begin{tabular}{ccccccccccc}
\hline $\mathrm{Al}$ & $\mathrm{Zn}$ & $\mathrm{Mn}$ & $\mathrm{Ce}$ & $\mathrm{Si}$ & $\mathrm{Fe}$ & $\mathrm{Cu}$ & $\mathrm{Ni}$ \\
\hline 0.20 & 0.30 & $1.3 \sim 2.2$ & $0.15 \sim 0.35$ & 0.10 & 0.05 & 0.05 & 0.007 & Balance \\
\hline
\end{tabular}

Table 2 Physical and mechanical properties of MB8 at room temperature

\begin{tabular}{ccccc}
\hline Density/g. $\mathrm{cm}^{-3}$ & Poisson's ratio & Elastic modulus/GPa & Tensile strength/MPa & Yield strength/MPa \\
\hline 1.78 & 0.33 & 45 & 264 & 196 \\
\hline
\end{tabular}

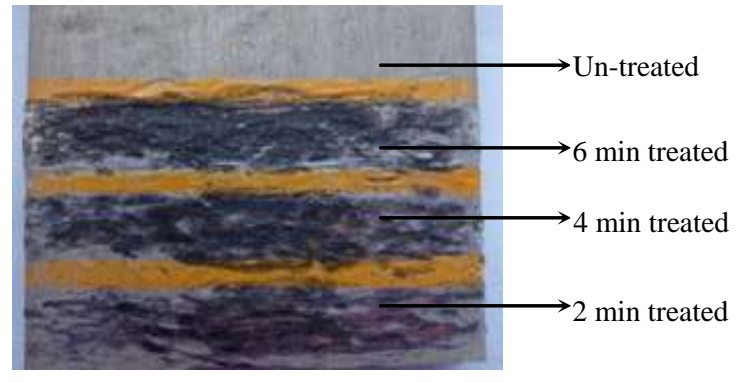

Fig.1 Treated and untreated specimens by ultrasonic impact treatment. The main reason of plastic deformation included crystal plane slip, twin, grain boundary movement, diffusion creep and so on ${ }^{[15]}$.

The Vickers hardness on the surface of treated and untreated MB8 was measured by the microhardness tester. Each sample was measured three times to take their average.

Data from the average micro-Vickers hardness tests for the treated and untreated specimens are shown in Fig.4. From Fig.4 it can be seen that the hardness of the treated specimen is markedly increased in the surface region. Actually this is a nearly linear relationship between the hardness and the impact time. 


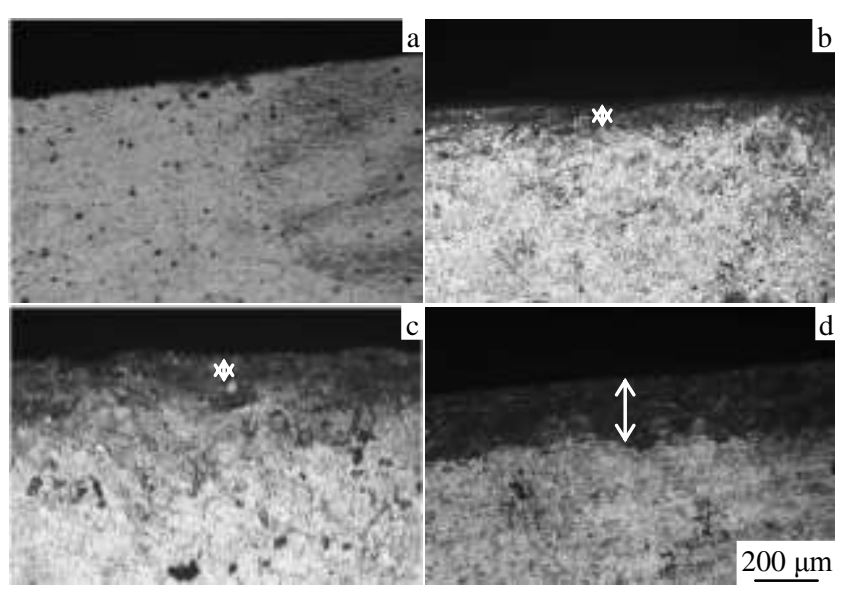

Fig.2 Microstructures of treated surface: (a) untreated; (b) UIT 1.2 A/2 min; (c) UIT $1.2 \mathrm{~A} / 4 \mathrm{~min}$; (d) UIT $1.2 \mathrm{~A} / 6 \mathrm{~min}$

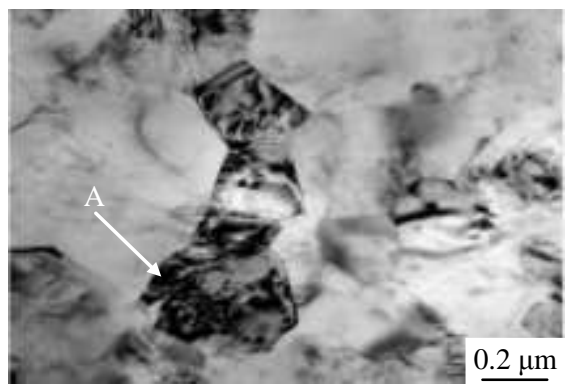

Fig.3 TEM bright field image of the specimen with UIT

The results of microhardness tests show that the microhardness of the treated specimen is about $102.8 \%$ harder than that of the untreated specimens when the UIT current is 1.2 $\mathrm{A}$ and time is $6 \mathrm{~min}$. The increase in hardness due to UIT can be attributed to both grain refinement and work-hardening effects on the surface layer following the Hall-Petch relationship $^{[16]}$. This relationship gives an empirical description of grain boundary strengthening in many metals and alloys and it is expressed as follows:

$$
H=H_{0}+k d^{-1 / 2}
$$

Where $k$ is a constant for a given material, $H_{0}$ is an appropriate constant associated with the hardness measurements, and $d$ is the mean grain size. This relationship has been confirmed in both theory and practice in many metallic materials with grain size in the micrometer scale ${ }^{[17]}$. The physical basis of this behavior is not fully understood, but it is believed to be associated with the inhibition of dislocation movement across grain boundaries and stress multiplication due to dislocation pile-up. Also, this relationship has been elucidated by several models such as the pile-up of dislocations ahead of grain boundaries, the grain boundary acting as a source of dislocations, and the effect of grain size on the dislocation density where dislocation density is inversely proportional to

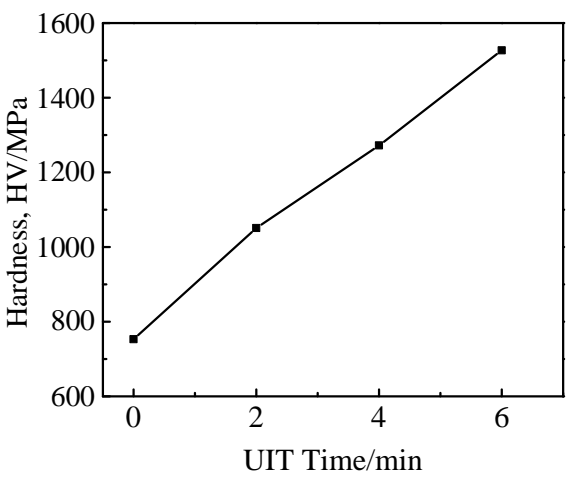

Fig.4 Relationship between hardness and UIT time

grain size ${ }^{[13]}$. The grain size strengthening effect in MB8 wrought $\mathrm{Mg}$ alloy, which has the hexagonal close-packed crystal structure, is high compared to those of other metals with the body-centered cubic and the face-centered cubic crystal structures since $\mathrm{Mg}$ has a large Taylor factor ${ }^{[18]}$. As noted before, longer impact time and higher impact current during the UIT process resulted in higher hardness compared with the shorter time and lower current because of dislocation movements and pile-up within the crystal structure of the metal material. When the test is $5 \mathrm{~N}$, dwell time is $10 \mathrm{~s}$, the impact current of $1.2 \mathrm{~A}$, and the impact time is $6 \mathrm{~min}$, the surface hardness of MB8 wrought magnesium alloy is increased by $102.8 \%$.

\subsection{Wear test}

The size of wear test specimen of MB8 wrought alloy is 7 $\mathrm{mm} \times 8 \mathrm{~mm} \times 30 \mathrm{~mm}$ which is cut from the treated and un-treated area on the rectangle plate are shown in Fig.1. The oppositional wear specimen is made of GCr15 steel, and its heat treatment procedure is quenching+low temperature tempering. The hardness of the down wear specimen is about 61 HRC. The shape and dimensions of the wear test specimen are shown in Fig.5.

All specimens were pre-worn for $2 \mathrm{~min}$ and then cleaned in acetone. The test results are shown in Table 3. The macro-wear surfaces are shown in Fig. 6 and the micro-wear surfaces analyzed by SEM are shown in Fig.7.

From Table 3, it can be found that with the UIT time increasing, the wear loss is decreased. Meanwhile, it is

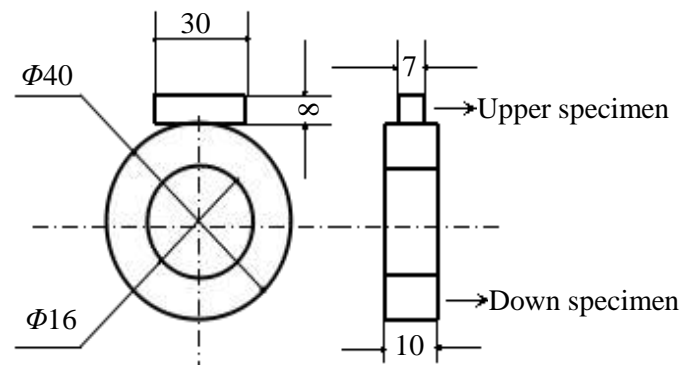

Fig.5 Shape and dimensions of wear test specimen 
Table 3 Wear test results of MB8 specimen

\begin{tabular}{cccc}
\hline $\begin{array}{c}\text { Current/ } \\
\mathrm{A}\end{array}$ & $\begin{array}{c}\text { Time/ } \\
\min \end{array}$ & $\begin{array}{c}\text { Measured mass } \\
\operatorname{loss} / \times 10^{-3} \mathrm{~g}\end{array}$ & $\begin{array}{c}\text { Average mass } \\
\text { loss } / \times 10^{-3} \mathrm{~g}\end{array}$ \\
\hline 0 & 0 & $2.7,2.9,2.7$ & 2.767 \\
1.2 & 2 & $1.8,2.2,1.9$ & 1.967 \\
1.2 & 4 & $1.6,1.7,1.3$ & 1.533 \\
1.2 & 6 & $1.1,1.7,1.2$ & 1.333 \\
\hline
\end{tabular}

obvious that the wear scars width on the macro-wear surface becomes narrower due to the increase of the UIT time in Fig.6. As it is observed in Fig.7, the wear track width is decreased significantly with increasing the UIT time. Wear tracks of all the treated specimens are narrower compared to that of the untreated specimen. Furthermore, the wear resistance of treated specimen is distinctly superior to that of the untreated. Most of the worn out surfaces consist of smooth strips showing scoring marks. Scoring marks are mostly attributed to the abrasion by the entrapped debris, and the deposits which are work hardened on the counter face ${ }^{[19]}$. From Fig.7a the ploughing is deepest and local place has cracks, which is generally known as abrasive wear. The experimental results show that the wear resistance of MB8 wrought Mg alloy could be improved by the UIT. Among all the specimens, the specimen, which has the highest hardness, possess the lowest mass loss and best wear resistance.

Table 3 shows the results of wear resistance of all specimens at the external load of $300 \mathrm{~N}$. It can be seen that the wear resistance of specimens which are strengthened by UIT is remarkably improved, especially for the specimen treated with impact time for $6 \mathrm{~min}$, and the wear resistance has been increased up to about $51.83 \%$ compared to the un-treated specimen. Therefore, the tested mass loss data shown in Table 3 confirm the microscopic observations shown in Fig.7.

The improvement in wear resistance of the treated specimens can be interpreted by Holms and Archards adhesive wear theory ${ }^{[20]}$ as:

$$
V=P \cdot W / H
$$

Which is applied to adhesive and abrasive wear, where $V$ is the wear volume loss per unit sliding distance, $W$ is the applied load, $H$ is the hardness of the materials, $P$ is the wear constant related to the wear mechanisms and the materials of the wear members. The wear loss obtained can be directly

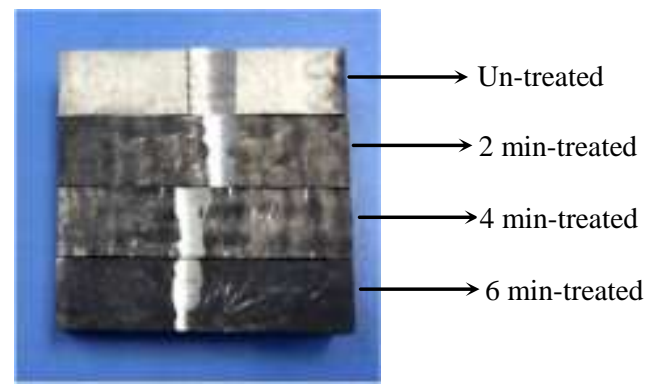

Fig.6 Worn surfaces of specimens after wear testing

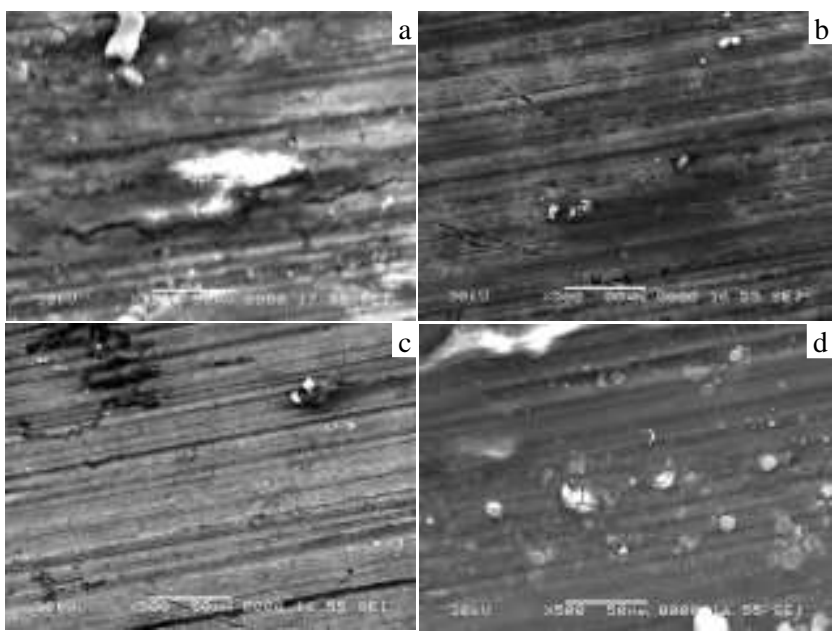

Fig.7 SEM images of the typical worn surfaces of the specimens with different impact parameters: (a) un-treated; (b) UIT 1.2 A/2 min; (c) UIT $1.2 \mathrm{~A} / 4 \mathrm{~min}$; (d) UIT $1.2 \mathrm{~A} / 6 \mathrm{~min}$

correlated to the hardness of the surface. Fine grain structure and compressive residual stress improve the surface strength of the material ${ }^{[21]}$. The compressive residual stress and high strength of fine grain material at the treated surface increase the wear resistant property compared to the untreated samples.

\section{Conclusions}

1) The microstructure on the treated surface of MB8 wrought magnesium alloy can be refined by UIT. After UIT process, severe plastic deformation is produced in the surface of MB8 alloy and the maximum depth of the plastic deformation layer is about $260 \mu \mathrm{m}$ in the current research.

2) The micro-hardness of MB8 wrought magnesium alloy could be greatly improved via the UIT process. The micro-hardness of the treated specimen is about $102.8 \%$ harder than that of the untreated specimen when the UIT current is $1.2 \mathrm{~A}$ and time is $6 \mathrm{~min}$.

3) The wear resistance of MB8 wrought magnesium alloy could be increased by the UIT process. When the UIT current is $1.2 \mathrm{~A}$ and the time is $6 \mathrm{~min}$, the wear resistance has been increased by about $51.83 \%$ compared to that of the un-treated specimen.

\section{References}

1 Hou L F, Wei Y H, Liu B S et al. Rare Metal Materials and Engineering[J], 2008, 37(3): 530 (in Chinese)

2 Wang W, Wang K S, Guo Q et al. Rare Metal Materials and Engineering[J], 2012, 41(9): 1522 (in Chinese)

3 Shen L D, Tian Z J, Huang Y H et al. Powder Metallurgy Technology[J], 2009, 27(1): 29 (in Chinese)

4 Sha W. Materials \& Design[J], 2007, 28(5): 1524

5 Du J, Li W F, Liu Y H et al. Tribology[J], 2004, 24(4): 341

6 Lim C Y H, Lim S C, Gupta M. Wear[J], 2003, 255(5): 629 
7 Liu H, Xue F, Bai J et al. Rare Metal Materials and Engineering [J], 2014, 43(3): 570 (in Chinese)

8 Wang W J, Hu J, Guo J et al. Wear[J], 2010, 311(1): 130

9 Zhang D Y, Fei Q Y, Zhao H M et al. Thin Solid Films[J], 2005, 484(2): 25

10 Hikmet A, Sadri S. Materials Characterization[J], 2007, 58(10): 917

11 He B L, Liu J, Wang B. Applied Mechanics and Materials[J], 2011, 80-81: 673

$12 \mathrm{Lu} \mathrm{K}, \mathrm{Lu}$ J. Materials Science and Engineering A[J], 2004, 375-377: 38

13 Auezhan A, Penkov O V, Pyun Y S et al. Tribology International[J], 2012, 54: 106

14 Nike O, Kati V, Vuokko H et al. Wear[J], 2014, 317(2): 225
15 Sun J L, Trimby P W, Liao X Z et al. Scripta Materialia[J], 2013, 68(7): 475

16 Amanov A, Cho I S, Pyoun Y S et al. Wear[J], 2012, 286: 136

17 Zherebtsov S, Salishchev G, Galeyev R et al. Materials Transactions[J], 2005, 46(9): 2020

18 Kim W J, Jeong H G, Jeong H T. Scripta Materialia[J], 2009, 61(11): 1040

19 Palash P, Arpan D, Sahoo K L. Materials \& Design[J], 2014, 54: 820

20 Wen S Z, Huang P. Tribology Principle[M]. Beijing: Tsinghua University, 2003 (in Chinese)

21 Yu Y X, He B L, Shi J P et al. Advanced Materials Research[J], 2013, 668: 835

\title{
超声冲击 MB8 镁合金的耐磨性与显微硬度试验
}

\author{
于影霞 ${ }^{1}$, 何柏林 ${ }^{2}$, 吕宗敏 ${ }^{1}$, 雷思涌 ${ }^{2}$, 夏崧崧 ${ }^{1}$ \\ (1. 华东交通大学, 江西 南昌 330013) \\ (2. 载运工具与装备教育部重点实验室, 江西 南昌 330013)
}

\begin{abstract}
摘 要: 采用 HJ-III 型超声冲击设备对 MB8 镁合金表面进行冲击处理, 利用高倍透射电子显微镜研究了超声冲击表层的微观组织及晶 粒细化机制。对经超声冲击处理和未冲击处理的 MB8 镁合金的耐磨性能进行了对比研究。采用扫描电镜和显微硬度计分别研究了超声 冲击处理对磨损表面形貌和显微硬度的影响。结果表明: 超声冲击使 MB8 镁合金的表面出现了严重的塑性变形, 塑变层深度约为 $180 \mu \mathrm{m}$, 表面组织明显得到细化。耐磨性能和显微硬度随超声冲击时间的延长而提高。与未冲击试样相比, 在冲击时间为 6 min 时, 冲击电流为 $1.2 \mathrm{~A}$ 时, 冲击试样的显微硬度和耐磨性分别提高了 $102.8 \%$ 和 $51.83 \%$ 。
\end{abstract}

关键词：超声冲击; MB8 镁合金; 微观组织; 硬度; 耐磨性能

作者简介: 于影霞, 女, 1964 年生, 硕士, 副教授, 华东交通大学机电工程学院, 江西 南昌 330013, 电话: 0791-87046137, E-mail: yyxhbl@163.com 